\title{
Falling off the Ladder? \\ Professional and Managerial Career Trajectories and Unemployment Experiences
}

\author{
Yaojun $\mathrm{Li}$
}

Two highly influential theories are in debate over the class character of professional and managerial employees in their work-life mobility. The 'employment relationship theory' holds that these employees have a service employment relationship with their employers, which will guarantee their career stability as a distinctive service class with no major internal divisions. Challenging this is the 'assets theory' arguing that underlying professional and managerial careers are two fundamentally different assets. Cultural assets facilitate the formation of a cohesive and secure professional middle class, whereas organizational assets will result in an insecure and marginalized managerial middle class. Exponents of the theories have conducted empirical research to support their arguments but, owing to the limitation of data and methods used, no direct dialogue is available. This paper seeks to bring about such a dialogue by using more appropriate data and methods to test the theories simultaneously and rigorously. The analysis focuses on professional and managerial career flows derived from complete work histories and on the vulnerability to unemployment across two decades (1973-92). The results show that, overall, the challenge to the employment relationship theory is not substantiated.

\section{Introduction}

The twentieth century witnessed great changes in the occupational structure in advanced capitalist societies. The most notable feature was the expansion of professional, administrative, and managerial positions and the contraction of working-class positions. In Britain, whereas threequarters of the workforce were in manual jobs and only one-tenth as many in professional and managerial positions in 1911, the former contracted and the latter expanded very rapidly, especially from the 1950s onwards (Price and Bain, 1988). By 1991, manual positions had dropped by over a half and professional and managerial positions increased by nearly three times so that there were almost as many people in the latter as in the former positions $(\mathrm{Li}$, 1997). Such changes have led to numerous debates and studies aimed especially at accounting for the class position of professionals and managers (Braverman, 1974; Bruce-Briggs, 1979; Gouldner, 1979; Wright, 1985; Butler and Savage, 1995). This paper will not discuss these but will focus on two highly influential theories that have been in debate in British sociology over the last two decades: the employment relationship theory put forward by Goldthorpe and his colleagues (Goldthorpe, 1982, 1987; Erikson and Goldthorpe, 1992), and the 'assets' theory supported by Savage and his colleagues (Savage et al., 1992). The two theories address many socio-economic and political issues, but the present paper will concentrate on the work-life mobility of professionals and managers. Patterns and trends of such mobility, in terms of both stability in 
advantaged social positions and vulnerability to long-term downward mobility, are of particular importance in understanding the mechanisms which generate the observed forms of class formation and class action.

The employment relationship theory holds that professional and managerial employees have the same 'service' employment relationship with their employers, which will engender similar patterns of career continuity and will distinguish them as a fairly unified 'service class' with no major internal divisions. The assets theory argues, however, that the two groups possess fundamentally different assets, which will put them into two distinct social classes with growing divisions: a cohesive and well-established professional middle class, and an insecure and marginalized managerial middle class. The two groups of theorists have conducted much empirical research to support their arguments but, owing to the limitation of the data and the different analytical frameworks they use, have not achieved a direct dialogue. This paper seeks to bring about such a dialogue by using a standardized operational framework, and more appropriate data and methods to test the competing claims.

Table 1 summarizes the basis of the arguments and the operational frameworks of the two theories. The employment relationship theory, regarded as the best of all existing sociological endeavours in terms of theory, utility, and validity (Rose and O'Reilly, 1997; Marshall et al., 1988; Evans, 1992), holds, following Renner (1953) and Dahrendorf (1964), that both groups are 'service' experts providing specialist knowledge to, or exercising delegated authority on behalf of, their employers, services prerequisite for the smooth and efficient running of modern organizations. In return for the services, they are compensated with secure employment, attractive remuneration, and distinctive prospects for career advancement. With regard to the career mobility of the employees, the theory argues that the service employment relationship would guarantee a distinctive security in their career trajectories. Once access to the class is obtained, both groups will have a high degree of career continuity and a very low degree of subsequent long-range downward mobility. Moreover, professionals will be highly likely to move into senior management as their career develops, which is a defining feature of service-class employment.

The employment relationship theory acknowledges differences within the service class just as within other broadly defined social classes, such as the intermediate or the working classes. Differences within the service class are supposed to lie both between the higher and the lower grades, and between the professional and the managerial sections. The former are called 'echelon' and the latter 'situs' relations. The echelon relations are viewed as representing a sort of social division of labour within the service class. Erikson and Goldthorpe state that 'Positions covered by Class I may be taken as those to which the largest responsibilities in decision-making attach and which will in turn offer the fullest range of beneficial conditions associated with the service relationship; while in the case of the lower-level positions of Class II, certain of these features may be attenuated' (1992: 43). Differences between professional and managerial situses, which presumably represent a technical division of labour within the class, are not emphasized. As Morris and Murphy put it, situses are 'equally valued functional categories of occupations' (1959: 231) that should not be invidiously compared. Goldthorpe explains that the term refers to "the functional context" of an occupation, or group of occupations, which may exert an influence on the lifestyles and patterns of action of their incumbents, independently of that of the class, or status, positions that they simultaneously hold' (1995: n. 5). Although the theory expects both echelon and situs effects in work-life trajectories, it would stress that such differences are of an intra-class kind, unrelated to the common employment relationship. In other words, the differences will be fairly small and comparable to those observed within the other main classes and, as such, will not constitute major divisions of an interclass kind.

The assets theory put forward by Savage and his colleagues is a direct and powerful challenge to the employment relationship theory. Drawing from Wright (1985) and Bourdieu (1984), the theory seeks to develop a new theoretical perspective to understand middle-class formation and action. Criticizing 'fashionable and unhelpful theories' of the service class, the authors argue that underlying professional, managerial, and petty-bourgeois class 

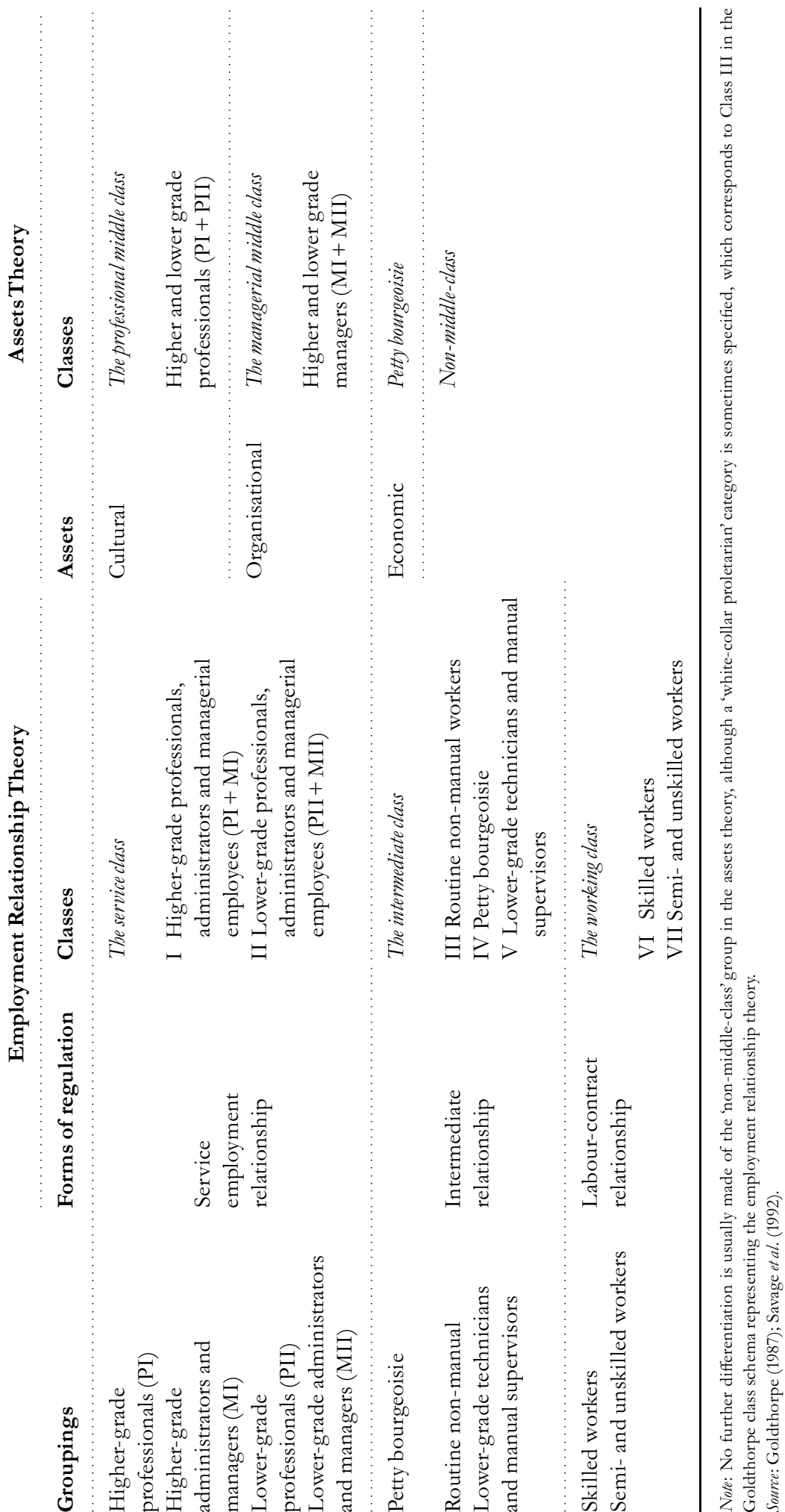
formation and action are three kinds of assets: cultural, organizational, and economic. Of greater importance are the relations between the first two assets, as 'middle-class formation is crucially concerned with the way in which cultural and organization assets relate to each other' (Savage etal., 1992: 18).

The assets theory views the professional and managerial relations as inter- rather than intraclass. Cultural assets are objectified in credentials, embodied in the habitus, and transferable from one context to another, whereas organizational assets are context-specific and non-transferable. As a result, professionals will form a stable and cohesive social collectivity but managers will be marginalized, with large numbers subject to long-range downward mobility in their career trajectories. To counteract the insecurity, managers will seek selfemployment as a main career strategy. The authors claim that their research demonstrates 'the continued depth and salience of the division between professional and managerial groups', and predict that 'any notion that a "mature" service class may become a salient social grouping in the near future is wrong. The trends largely operate in the other direction, towards a deepening of the split between professionals and management' (Savage et al., 1992: 216, 217).

The exponents of the theories have conducted empirical research to support their arguments, but owing to the limitations of the data and the operational frameworks used, the results they report are not comparable. For example, Goldthorpe (1987: Table 5.1), using the Oxford Mobility Study (OMS) of 1972, shows a very high degree of career continuity for those who reached service-class positions in their first jobs: 82 per cent were still in service-class positions in their current jobs. But the OMS had no data on the majority ( 65 per cent) of the service-class men whose access to the class was indirect and whose career trajectories cannot be explored in the comparison between first and current jobs nor compared with those of the direct entrants. Mills (1995) uses the complete work histories in the Social Change and Economic Life Initiative (SCELI) of 1986 and the Government Social Survey (GSS) of 1949 to study professional and managerial career changes over time. With regard to the SCELI, he finds an increase in mature entrants to lower professions and a more common transition from management to professions than the other way round (Figure 6.5a and Table 6.2). The former is explained as reflecting an increasing blurring of professional and managerial distinctions, and the latter as arising from the lower professionals' inflows from 'lower management and administrative jobs' (1995: 113). Important as they are, Mills's findings are derived from cumulative mobility tables rather than demonstrating professional and managerial career developments as they were being unfolded. This point is acknowledged by Mills himself, in that the evidence on professions is 'not conclusive because the profiles tell us only about the stock of professionals at each age and say nothing about flows into and out of professional positions' (1995: 106-7, emphasis in the original). The same applies to the managers.

Savage et al. (1992) use the Longitudinal Study (LS) which links the Census records of 1 per cent of the population between 1971 and 1981. Focusing on 'survival' rates in the ten-year period, they find managers 'have the most downward mobility', which they believe confirms their expectation that cultural assets 'convey greater security than organization assets' (1992: 141). But as the LS does not contain complete work-life histories of the respondents, the findings can hardly be used as an effective challenge to the employment relationship theory.

\section{Data and Methods}

In view of the above and given the nature of the debate, this paper will use more appropriate data and techniques to test the two competing theories. We use the complete work-life histories from the Main Survey of the Social Change and Economic Life Initiative (SCELI, 1986) to compare the career flows of different service-class groupings, and crosssectional data from the General Household Survey (GHS, 1973-1992) for 20 consecutive years to compare the vulnerabilities to unemployment both within the service-class groupings and between the major social classes. In terms of techniques, we test the differences both between any two groups (or classes) and between situs and echelon relations simultaneously. (The results of the significance 
tests are presented as Appendix Tables at the website bttp://les1.man.ac.uk/ccsr/staff/yaojun.htm.)

The SCELI contains information on the complete work-history of 6110 respondents aged 20 to 60 in six towns or cities in Britain: Aberdeen, Coventry, Kirkcaldy, Northampton, Rochdale, and Swindon. Of these respondents, 2652 were, or had been, in professional or managerial positions. Data on these respondents are organized according to the 'entry' status. Professional and managerial entrants are defined, respectively, as those who entered professional (managerial) positions for the first time in their working lives without having ever worked in managerial (professional) positions, regardless of what other class positions they had held prior to the entry. Career mobility is explored by tracing the class positions held in each year between entry and the date of the survey. In total, 42 years are identified, but as the sample size becomes increasingly small for people with long career histories, a cut-off point at the 30th year is adopted $(\mathrm{N}=403)$. Data on 29 years are analysed, from the second to the thirtieth year after entry. (The seven people who gave no information on the year of entry are omitted from the analysis.) The data make it possible to compare the degrees of career stability, situs-crossing, and long-range downward mobility of the two groups. Apart from the career trajectories in the 'yearly' sense, mobility in the job changes is analysed, in order to see which group was most likely to lose 'service-class'status in such changes. As many people did not change jobs between their professional or managerial entry and the time of interview, the Ns get progressively smaller with the number of job changes. A cut-off point is made at the eighth job after entry $(\mathrm{N}=452)$.

The GHS is a large-scale survey of the general population resident in private households in Great Britain. To be compatible with the SCELI, the data used are confined to people aged 20 to 60 and resident in Great Britain. There are, on average, 7031 men and 7324 women respondents in each of the twenty years, even with the constraints imposed. The data are particularly suitable to the analysis of unemployment, arguably the most serious form of social deprivation in people's lives. Unemployment rates go up and down and no single year is representative. When the rates are very low, all sections of the working population are generally safe from job loss.
In times of very high unemployment, people in different social positions have different fates. It is thus essential that analysis be conducted over a fairly long period of time and that a differentiation is made between 'general' (defined as any kind of unemployment) and 'long-term' unemployment (that which lasts over a year).

The coding of the class variable follows exactly the same procedure as used by the two groups of theorists. As the Hope-Goldthorpe (1974) 36 categories are available in the SCELI and the Social Economic Groups (SEGs) in the GHS, and as the SEGs conform very well to the class groupings used (Martin, 1997), we follow Goldthorpe (1987: 40-2) and Savage et al. (1992: 230-1) in translating the categories and the SEGs into the class groupings shown in Table 1. Because the service class is conceptualized as a class of employees (Goldthorpe, 1982, 1987, 1995), large employers and self-employed professionals are omitted throughout the analysis, namely, Hope-Goldthorpe categories 1, 7, and 9 and the SEGs 1.1 and 3. Finally, as both groups of theorists conduct their research for men and women separately where data allow, we follow suit.

\section{Analysis}

As noted above, the employment relationship theory allows for both echelon and situs effects as intra-class. Such situs relations are, however, held as inter-class in the assets theory. If, in the analysis, the differences between professionals and managers (situses) persist in spite of the echelon effects being controlled for, the evidence is against the employment relationship theory. Conversely, if the differences do not persist, the challenge by the assets theory is not substantiated, which would mean that the situses are no more divided than the echelons, and that both the situs and the echelon relations should be viewed as intra-service-class relations.

\section{Career Trajectories}

The employment relationship theory claims that, for men at least, professionals and managers alike will have distinctive careers, that professionals will increasingly find themselves in managerial positions, and that long-range downward mobility 
will be rather uncommon (Goldthorpe, 1982, 1987). The assets theory predicts a high degree of career stability for professionals but a rather low degree for managers, who will be downwardly mobile in 'relatively high proportions' and whose 'main career strategy is to convert organization assets into property assets through entrepreneurship' (Savage et al., 1992: 141), i.e., to move to petty-bourgeois positions.

Data in Panel (A) of Figure 1 on the male professional entrants show a high degree of stability in service-class positions in the work-life trajectories: on average, 74 per cent remained in professional or managerial positions in their working lives (the top line in the panel). This pattern supports the claims of both theories. A most interesting feature is, however, that, just as the employment relationship theory predicts, the professionals showed a strong propensity to leave professional, and to enter managerial, positions in the course of their careers. In the second year after entry, only 3 per cent were found in managerial positions but in the thirtieth year, 28 per cent were so found. The differential between their being found in professional and managerial positions narrowed from 84 percentage points in the former to a mere 15 points in the latter year. The convergence between the professional and the managerial lines in the panel is self-evident, which supports the employment relationship theory beyond doubt. It also indicates that managerial positions may not be as risky or intrinsically undesirable as the assets theory would suggest.

Did the managerial entrants have a comparable career life? Data in Panel (B) of Figure 1 show that their overall stability in service-class positions was, albeit somewhat lower than that for the professionals, quite high in itself and fairly stable. On average, 65 per cent were found in such positions in the career trajectory. They were more likely than the professionals to experience long-range downward mobility into the working class: 16 and 9 per cent on average respectively. Evidence in this regard suggests some support for the assets theory, but there are other features in the panel which run counter to the theory. They were much more likely to stay in the service- than to fall into working-class positions. An increasing proportion was also found in professional positions, from a mere 3 per cent in the second year to around 13 per cent between the sixteenth and the twenty-second years. And they were as unlikely as the professionals to move into petty-bourgeois positions. Indeed, in most of the years, they were only half as likely to move into self-employment as into professions. This suggests that, for them, professional positions were more of an attraction, or at least less of a barrier, than pettybourgeois ones. For whatever reasons, neither managerial nor professional entrants sought selfemployment as a 'main career strategy'.

As noted earlier, the employment relationship theory was mainly developed from studies of male mobility patterns, although both groups of theorists analysed women's mobility where data were available. One may ask how the theories apply to women's careers. Data (Figure 2) show that the women professionals had a fairly high, and nearly stable, pattern of subsequent stability in serviceclass employment (Panel A). On average, 70 per cent were found in service-class positions in each year after entry, which is higher than the proportion of the male managerial entrants discussed earlier. About 20 per cent were found in routine-nonmanual and manual-supervisory positions of Classes III\&V (18 and 2 per cent respectively on average). They were also increasingly more likely to move into managerial than into petty-bourgeois positions. For instance, a mere 1 per cent were found in management in the second year but 11 per cent were so found in the thirtieth year, whereas the proportions found in petty-bourgeois positions never reached 5 per cent in any of the years.

The women managers (Panel B of Figure 2) presented the most striking contrast to the other groups. Their stability in service-class positions precipitated sharply from the second to the twelfth year, from 90 to 49 per cent, and then stabilized at around 45 per cent. Large numbers moved into routinenon-manual (Class III) positions (only a very small proportion, between 2 and 5 per cent, were found in the manual supervisory positions of Class V). But it is also noticeable that they were as likely to move into professions as their professional sisters were to move into management, and that both groups were equally unlikely to move into pettybourgeois or working-class positions.

The greatest difference between women professional and managerial groups' career lives thus lies in the latter's propensity to go to routine nonmanual positions. Does this support the 


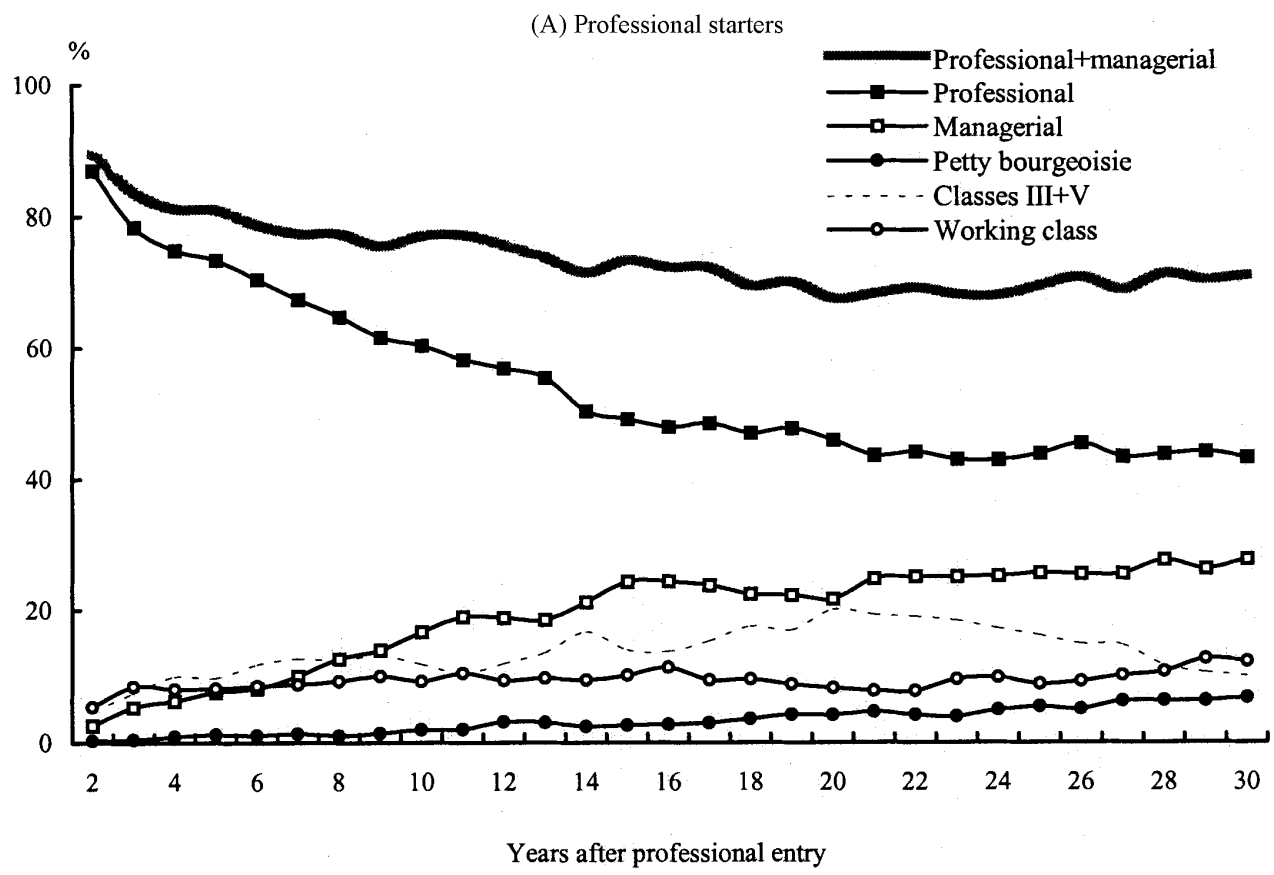

(B) Managerial starters

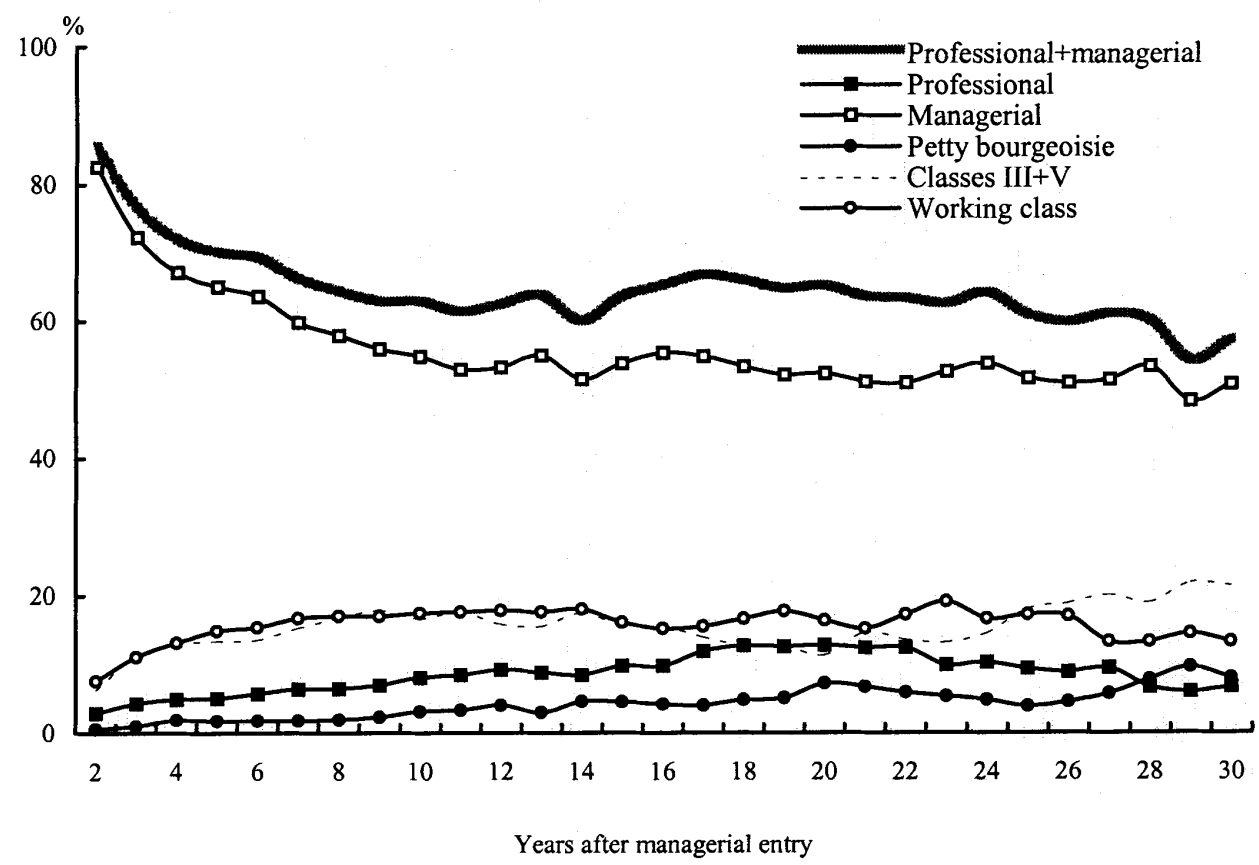

Note: Class III=routine non-manual workers; Class V=lower-grade technicians and manual supervisors. Source: The SCELI Main Survey (1986).

Figure 1. Career mobility for men: proportions found in different positions in each year afterprofessional or managerial entry 


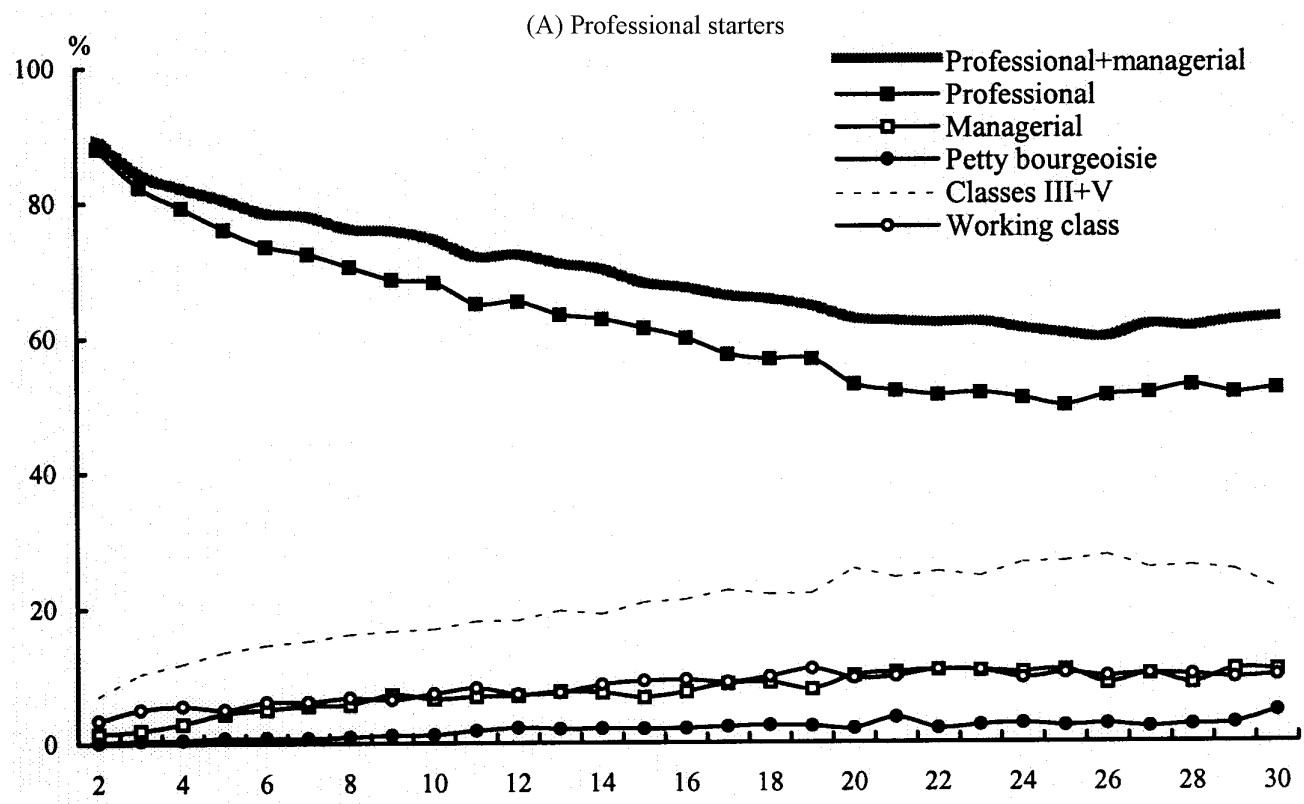

Years after professional entry

(B) Managerial starters

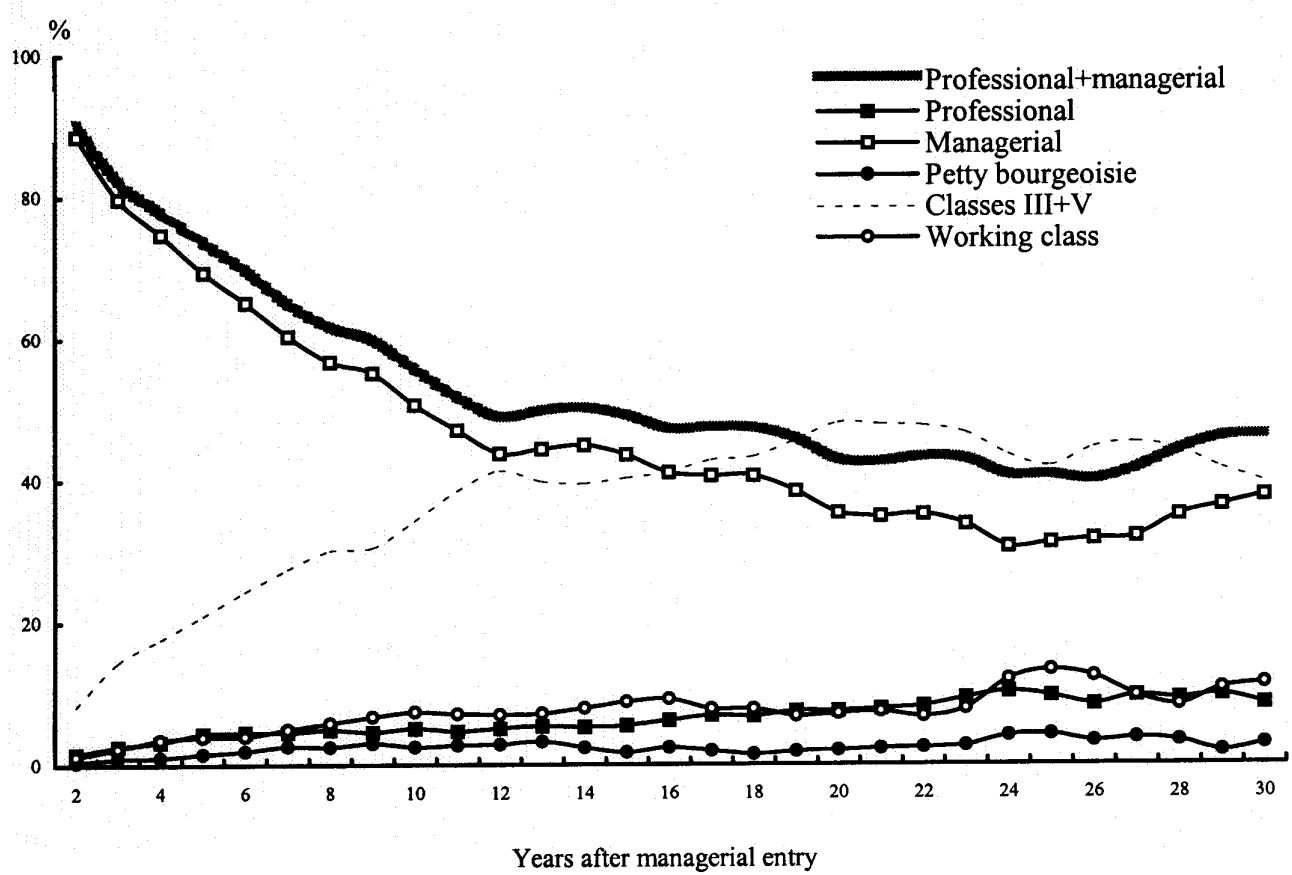

Source: Same as in Figure 1.

Figure 2. Career mobility for women: proportions found in different positions in each year after professional or managerial entry 
employment relationship theory or the assets theory? On the face of it, it supports the latter, as it is claimed that 'women are crucially dependent upon educational credentials, and hence cultural capital' (Savage et al., 1992: 143). But the question remains as to why cultural and organizational assets should have such different effects on women. Comparing the patterns in the two figures, one can immediately see that the women managers were not only much more likely to fall out of the service class than the male or female professionals, they were behind the male managers to a fairly similar extent. It seems the case that the assets theory is not doing a better job in this regard than the employment relationship theory, which does recognize the intermittent nature of women's employment because of family formation and child-rearing (Goldthorpe, 1984). If organizational assets per se entail an innate career insecurity, it would be difficult to explain why the same assets would effect differences between the two managerial groups to such an extent. As noted above, only about 45 per cent of the female, but 62 per cent of the male, managerial entrants were found in service-class positions from the twelfth year onwards. As managerial, unlike professional, employment does not usually allow for part-time work, it is reasonable to suggest that many of the women managers were compelled to leave their positions to fit in with family formation and child-rearing activities. Organizational prejudices (Wajcman, 1996), or the relative lack of 'family friendly' working-hours policies in many organizations (Elliott et al., 2000), may have affected women managers more than women professionals.

The discussion so far has focused on the professional and managerial career trajectories in temporal order. Although necessary for testing some of the competing claims by the theories, the evidence is not sufficient. As seen earlier, the employment relationship theory posits an echelon effect alongside a situs one within the service class, but it is neglected in the above analysis. It would be preferable to conduct an analysis on echelon-situs effects for the men and the women entrants separately. But as only 35 per cent of the male, and less than 11 per cent of the female, entrants gained access to the service class via the higher grade (Class I), the sample size shrinks rapidly, making patterns unstable. In view of this, the significance test for the situs- echelon effects is conducted by combining the male and the female entrants, which is less than desirable but is the only sensible way to proceed. To simplify the matter, only stability in service-class, and mobility to working-class, positions in each year are analysed. A careful look (Appendix Table 1 on the website) shows that, when the echelon effects are controlled for, the situs effects are mostly non-significant. We have seen the lack of differences, for men and women alike, in mobility to petty-bourgeois positions. The overall conclusion is, then, that even though considerable situs differences were manifested when no echelon effects were considered, such differences were on the whole nonsignificant once the latter were taken into account. In other words, the situs effects within the service class were generally no more divisive than between the echelons.

We have looked at the positions held by the professionals and the managers in each year since their service-class entry. Another perspective is to look at the positions they held in each job since entry. As many of the entrants ( 35 per cent) did not, for one reason or another, change jobs between the time of entry and the time of interview, the proportions found in the service class will thus be lower, and those in other positions higher, in each of the job changes. For this reason, the results on the jobchangers' stability reported here are lower than the overall stability in the job-to-job changes reported in Marshall etal. (1988: Table 5.13).

The general pattern of career mobility through job changes for the male professionals and managers (Figure 3) is similar to that shown in their yearly profiles, although the proportions found in serviceclass positions were lower in each of the job changes. Among those with job changes, around 65 per cent of the professionals were found in the service class on average, as against 54 per cent for the managers. The data again show that the professional starters were increasingly likely to move into managerial, and decreasingly likely to stay in professional, positions; that the managerial starters were as unlikely as the professionals to become small employers; and that both groups were much more likely to stay in the service class than to experience long-range downward mobility into the working class.

The career profiles of the female professionals and managers in their job changes (Figure 4) are 
(A) Professional starters

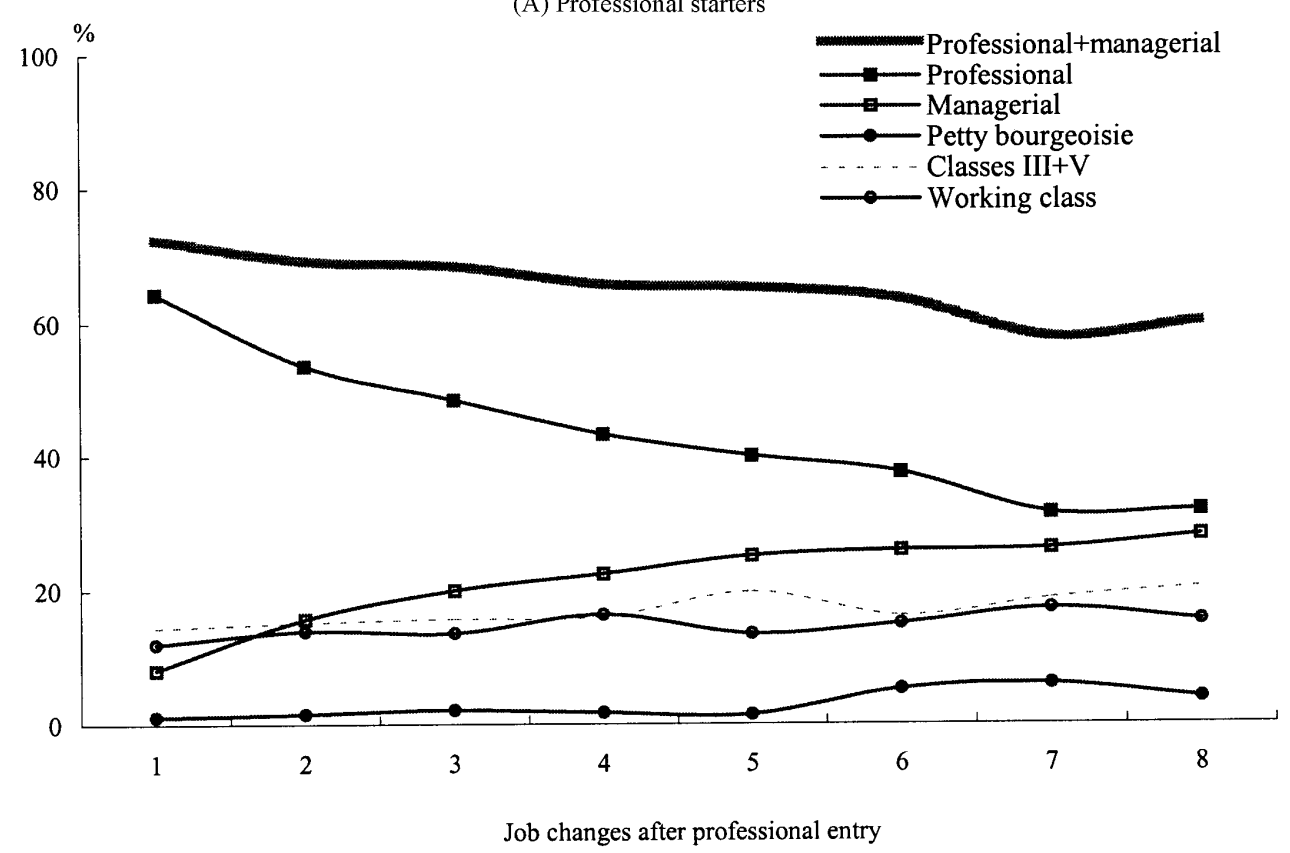

(B) Managerial starters

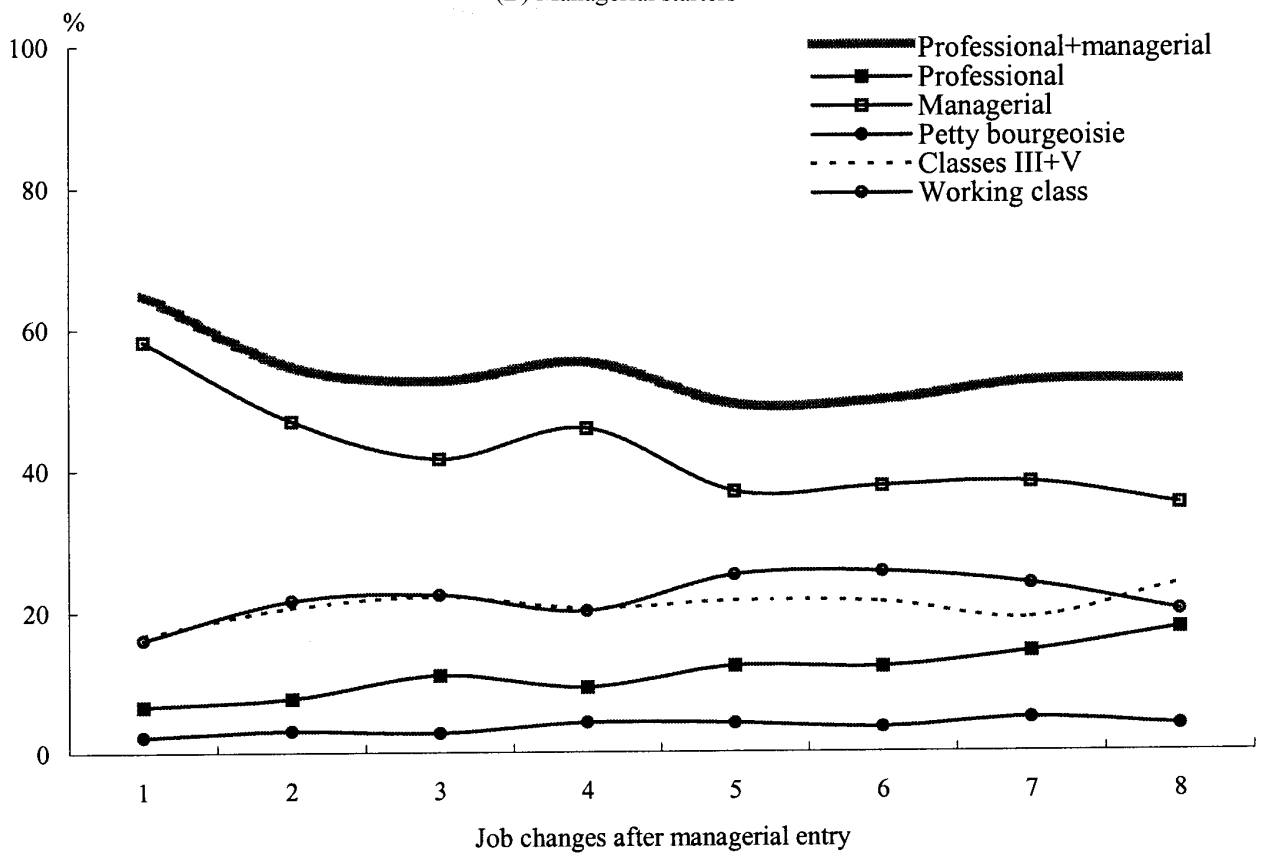

Source: Same as in Figure 1.

Figure 3. Career mobility for men: proportions found in different positions in each job change afterprofessional or managerial entry 

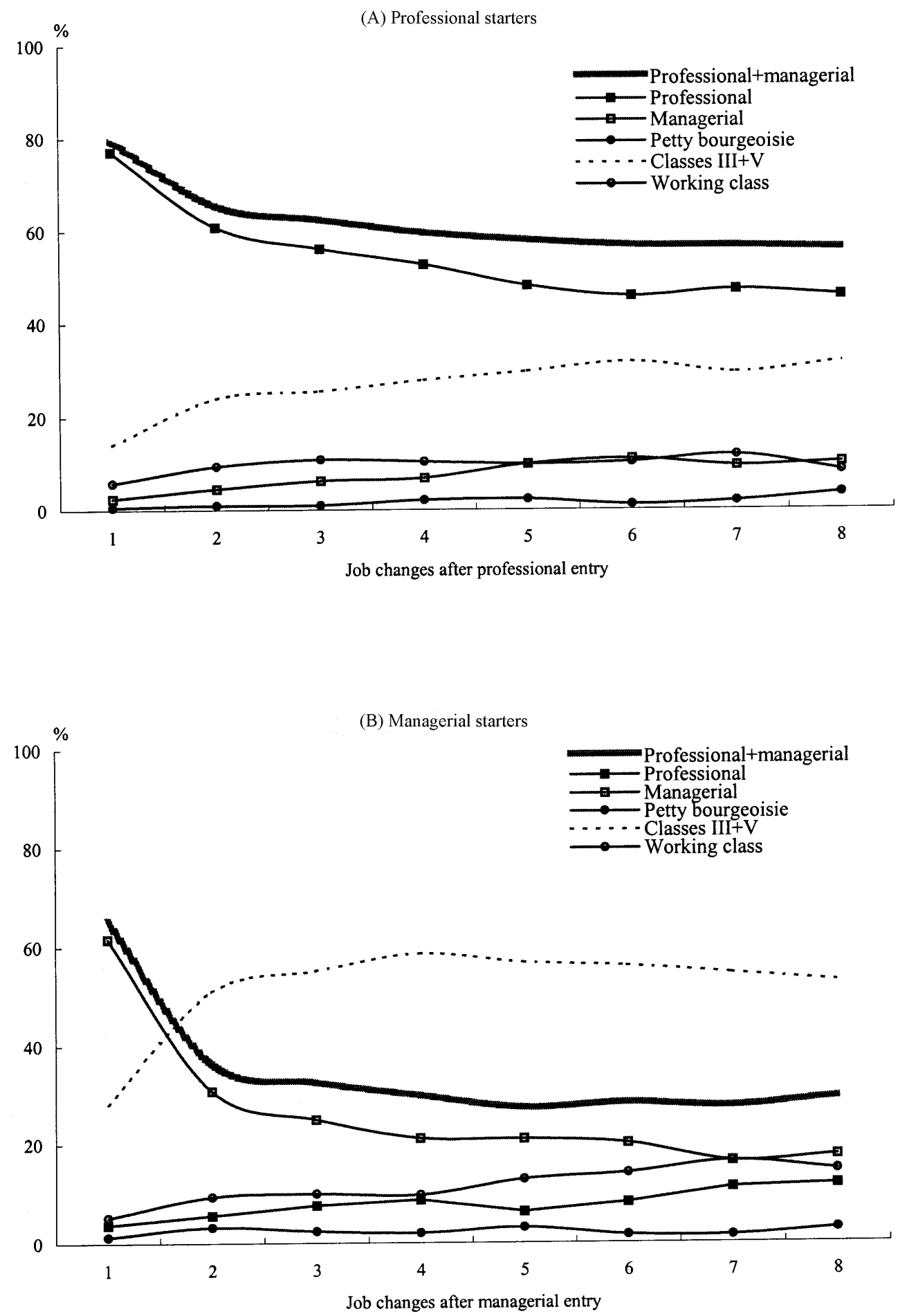

Source: Same as in Figure 1.

Figure 4. Career mobility for women: proportions found in different positions in each job change after professional or managerial entry 
again similar to those in the temporal unfolding, especially for the former. Women managers were less likely to stay in the service class than to move into routine-non-manual positions, especially from the second job change onwards. However, they were still twice as likely to stay in service-class as to move into working-class positions.

Given the degree of the professionals' propensity to move into management and the lesser but still noticeable extent of the managers' movement into professions in the course of their careers, it could be expected that much 'infiltration' would have occurred. This was indeed the case. Overall, 29 per cent of the men currently, i.e. in 1986, found in managerial positions had had professional experience and 11 per cent of those currently in professional positions had been managers, the corresponding figure for women being 18 and 9 per cent respectively. Furthermore, there was a clear 'life-course' effect. For the male managers, the proportions with professional experience increased from 23 per cent for the youngest cohort (aged $20-30)$ to 32,33 , and 26 per cent for the other cohorts in the 10 -year bands. (The male professional entrants with 42 years' history of serviceclass employment were more likely to be found in managerial than in professional positions: 50 and 33 per cent respectively.) The proportions of professionals with managerial experience also increased with age, from 6 to 16 per cent from the youngest to the oldest cohort. A similar feature, albeit to a lesser extent, is found for the women professionals and managers. The results would pose no difficulty for the employment relationship theory, but the class character of the ex-professionals and the ex-managers, and the extent of such infiltration, would be hard for the assets theory to explain.

Both groups of theorists would expect educational differences between professionals and managers. For Goldthorpe and his colleagues, professionals and managers have the same class position even though they have different educational levels. For the assets theorists, managers will continue to have organizational assets even when they have obtained higher qualifications. For present purposes, it is crucial to see first, whether similarly qualified professionals and managers would have similar career trajectories; and secondly, how educa- tion was shaping the echelon and situs relations within the service class over time.

Table 2 shows the effects of education on the professional and the managerial entrants' stability in the service class and downward mobility into the working class in their present (1986) positions, controlling for entry and gender. The results suggest that, when educational qualifications are controlled for, there is no significant difference between the entry groups. In other words, given the same educational levels, it did not matter whether someone started as a manager or a professional. Turning to the role of education in shaping the echelon and situs relations within the service class, we again find evidence supportive of the employment relationship rather than the assets theory. Further analysis using the GHS (1973-92, details available on request) shows that, throughout the period, the service class was increasingly credentialled; that, at least in the case of men, managers were catching up with professionals in terms of educational qualifications; and that, again for men, degree-holders were increasingly likely to be found in managerial rather than professional positions, whereas the proportions found in the two echelons retained roughly the same distances. Thus, the increasing stock of cultural assets in society benefited managers as well as professionals and the interplay of the cultural 'flows' helped integrate the situs relations.

\section{Unemployment Experiences}

The end of the economic boom in the 1950s and the 1960s and the return of mass unemployment in the succeeding decades may have had a serious effect on the life-chances of the working population. A sizeable portion of people were faced with greater insecurity and many remained unemployed for a long time. Yet in spite of this, the two theories would argue that unemployment hazards would affect different social groups in different ways. For the employment relationship theory, unemployment, especially when at a high level nationally, would be a working-class fate, whilst members in the service class would be largely exempted. For the assets theory, managers would not only be more likely than professionals to face job cuts arising from 
Table 2. Logistic regression of the effects of entry status, educational qualifications, and sex on stability in service-class positions and long-term downward mobility into working-class positions in the present (1986) class

\begin{tabular}{|c|c|c|c|c|c|c|}
\hline & \multicolumn{3}{|c|}{ Stability in the service class } & \multicolumn{3}{|c|}{ Mobility into the working class } \\
\hline & b & s.e. $^{\mathrm{a}}$ & o.r. ${ }^{b}$ & b & s.e. $^{a}$ & o.r. ${ }^{\mathrm{b}}$ \\
\hline \multicolumn{7}{|l|}{ Entry } \\
\hline $\begin{array}{l}\text { Prof. } \\
\text { Mgr. (base) }\end{array}$ & 0.10 & $(0.09)$ & 1.11 & 0.14 & $(0.15)$ & 1.14 \\
\hline \multicolumn{7}{|l|}{ Education } \\
\hline Degree & $2.20^{* * *}$ & $(0.20)$ & 8.99 & $-2.69 * * *$ & $(0.46)$ & 0.07 \\
\hline Professional & $1.91 * * *$ & $(0.15)$ & 6.76 & $-2.25^{* * *}$ & $(0.34)$ & 0.11 \\
\hline A\&O levels & $0.66^{* * *}$ & $(0.10)$ & 1.93 & $-1.09 * * *$ & $(0.17)$ & 0.34 \\
\hline \multicolumn{7}{|l|}{ Voc. + none (base) } \\
\hline \multicolumn{7}{|l|}{ Sex } \\
\hline $\begin{array}{l}\text { Men } \\
\text { Women (base) }\end{array}$ & $0.49 * * *$ & $(0.09)$ & 1.63 & $0.46^{* *}$ & $(0.14)$ & 1.58 \\
\hline Constant & 1.19 & $(0.06)$ & & $-3.11 * * *$ & $(0.15)$ & \\
\hline Pseudo $\mathrm{R}^{2}$ & $\begin{array}{c}0.18 \\
(\mathrm{~N}=2652)\end{array}$ & & & $\begin{array}{c}0.12 \\
(\mathrm{~N}=2652)\end{array}$ & & \\
\hline
\end{tabular}

Notes: 1: Prof.=Professionals; Mgr.=Managers; 2: Degree=first degree or above; Professional=professional qualifications like teaching and nursing below degree; A\&O levels=A Level, O Level, or equivalent; Voc. + none=vocational qualifications such as city and guilds, SCOTBEC/SCOTVEC, clerical and commercial, trade apprenticeship, and professional qualification without sitting exam; or no qualifications.

${ }^{a}$ s.e. $=$ standard error; ${ }^{b}$ o.r. $=$ odds ratio.

$* * \mathrm{p}<0.01 ; * * * \mathrm{p}<0.001$.

Source: The SCELI Main Survey (1986).

organizational restructuring and delayering, but also, owing to their lack of transferable skills, they would find it much harder to obtain re-employment. Their marginality and insecurity would be clearly manifested, especially in times when unemployment runs rampant. The following discussion of patterns and trends in general and long-term unemployment focuses on the differences both among groupings within the service class, and between the major classes: the service, intermediate, and working classes. The petty bourgeoisie are omitted from the analysis as, in this regard, they are peripheral to the debate.

Data on general and long-term unemployment for men (Figure 5) presents, very clearly, the picture predicted by the employment relationship theory. Panel (A) on general unemployment shows that the service class had the lowest rates throughout the two decades and the working class had the highest, with rates for the intermediate classes staying in between. On average, the service class were less than half as likely as the intermediate, and less than one-quarter as the working class, to be unemployed. In 17 of the
20 years (from 1976 onwards), the rates for the working class never dropped below 5 per cent whereas in none of the 20 years did the rates for the service class reach the 5 per cent level. When the working class were hardest hit throughout the 1980s and in the early 1990s (11-16 per cent), the service class were little affected (around 3 per cent in the 1980s and slightly over 4 per cent in the early 1990s). In the whole of the two decades, the class differences manifested themselves very clearly. With regard to differences among the service-class groupings, the clearest indication is the very low probability of unemployment for any of the groupings, although it is also evident that, especially in years with high rates for all classes such as from 1983 to 1988 and again in the early 1990s, there were some fairly noticeable echelon differences, but almost no sign of situs differences. Men in Class I were on the whole least likely to be found out of work. When we turn to the patterns and trends in long-term unemployment (Panel B of Figure 5), the same picture emerges, except that the scales are smaller for all groups. 
(A) General unemployment

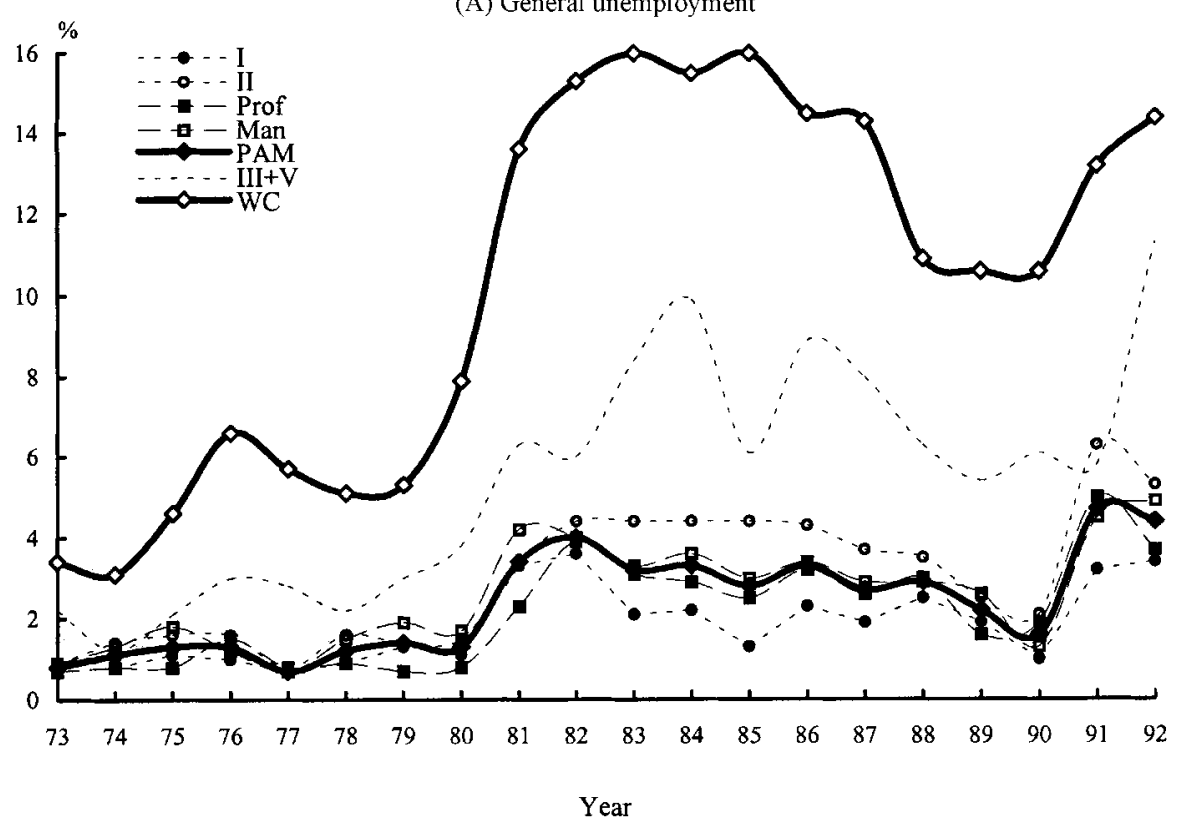

(B) Long-term unemployment lasting over a year

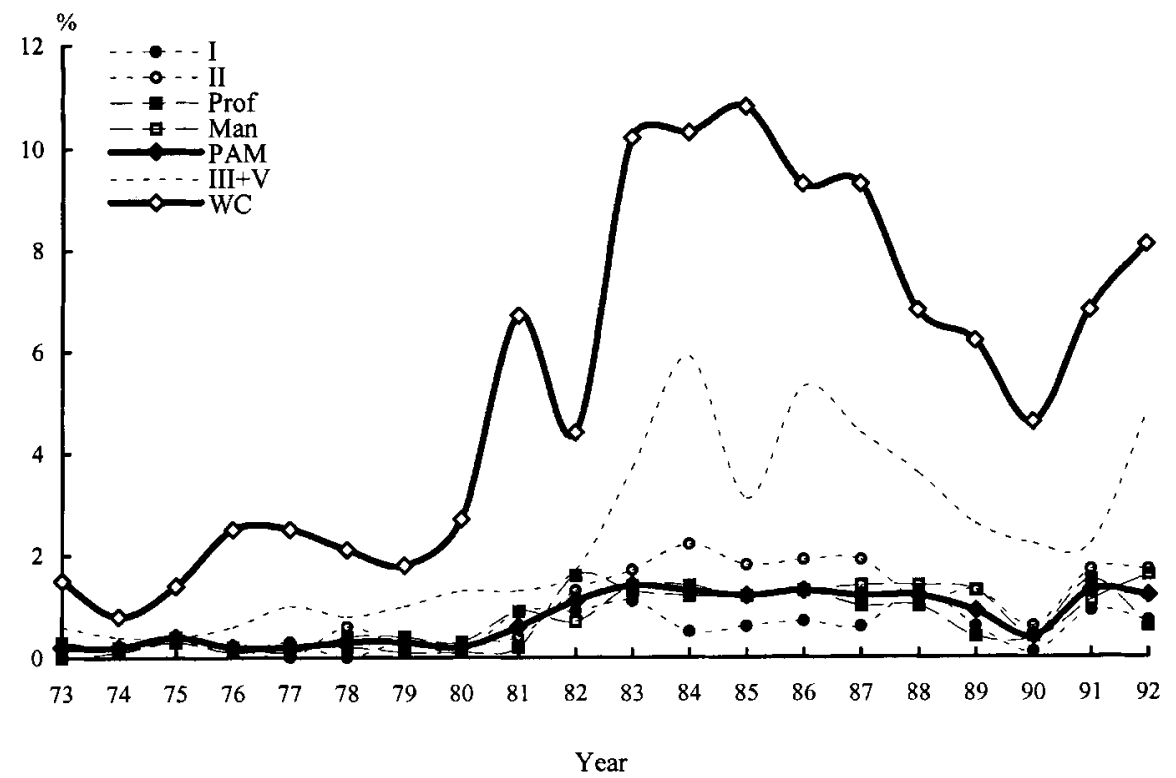

Note: Class I=higher-grade professionals and managers; Class II=lower-grade professionals and managers; Prof-professionals; Man=managers; $P A M=$ professionals and managers; III+V=routine non-manuals; and lower-grade technicians and manual supervisors; $\mathrm{WC}=$ the working class.

Source: The GHS (1973-1992).

Figure 5. Unemployment hazards of men 
The result of significance tests for the men's general and long-term unemployment (Appendix Table 2 shown at the website) confirms this. With regard to general unemployment, the class effect is indisputable: as compared with the service class, the working class were significantly more likely to experience unemployment in each of the 20 years; and the intermediate class were significantly more likely to lose jobs in the 17 years. Within the service class, managers were significantly more likely to be unemployed than professionals in 2 years only (1979 and 1981), but being in the lower echelon raised the risks in 7 of the years (1983 to 1987, and 1991 and 1992). When the situs and echelon relations were tested together, the results were generally nonsignificant, although the echelon relations were significant in 2 years even after taking into account the situs effects (1985 and 1991), and in none of the 20 years were there any significantly greater situs than echelon differences. Panel 2 of the table on longterm unemployment shows basically the same features. Patterns and trends of men's general and long-term unemployment thus reveal the greatest differences as lying between the service- and the working-classes, with the intermediate groups in between. Differences within the service class were very small. All this lends very strong support to the statements that 'unemployment, even when at a high level, remains predominantly a working-class fate', and that 'to occupy a working-class position so greatly increases the risk of experiencing the rather decisive form of downward social mobility that becoming - and perhaps for long remaining unemployed must be taken to represent' (Goldthorpe, 1987: 269, 270).

Turning to patterns and trends of general and long-term unemployment for women (Figure 6), we find essentially the same picture as for men, although women were generally less likely to be unemployed as large numbers of them were not in employment. In 1983, for example, 4 per cent of the service class were found in general unemployment as compared with 11 per cent for the working class; and the corresponding figures are 1 and 5 per cent respectively in long-term unemployment. Detailed analysis (Appendix Table 3 on the website) shows that in both kinds of unemployment, workingclass women were significantly more likely to be out of work than service-class women in most of the years covered (in 18 out of the 20 years in general, and in 16 years in long-term, unemployment). Similar features, albeit to a lesser degree, hold in the comparison between the intermediate and the service classes. With regard to the service-class groupings, the most prominent feature is again the lack of difference between the situses throughout the period. Differences between the echelons were, however, more noticeable. Those in the lower echelon, where the majority of the service-class women were found, were significantly more likely than those in the higher echelon to have general unemployment in 7 years, and long-term unemployment in 5 years. When the situs and echelon relations were tested simultaneously, there were significantly greater echelon than situs differences in 5 years in general unemployment, although no such differences in long-term unemployment. All this shows that unemployment of both kinds, for women just as for men, went along class lines, especially between the service and the working classes; that the professionals were little different from the managers; and that the within service-class differences ran somewhat deeper between the echelons than between the situses.

\section{Discussion}

This paper has sought to conduct a simultaneous test of the claims of the two main theories on the class character of professional and managerial employees: namely, the employment relationship and the assets theories. The analysis focused on the career stability and the subsequent long-range downward mobility of the two groups. The complete work-life histories in the SCELI and in the GHS data for 20 consecutive years are used for the purpose. The coding for class groupings is adopted from the very procedures used by the exponents of the theories, and a method is employed to test the competing claims both independently and in a direct comparison. The results obtained are therefore unbiased. How, then, does the evidence fit with the theories?

A brief review may help to bring into sharper relief the main arguments and findings. The employment relationship theory holds that service-class members, at least men, will have a high degree of 
(A) General unemployment

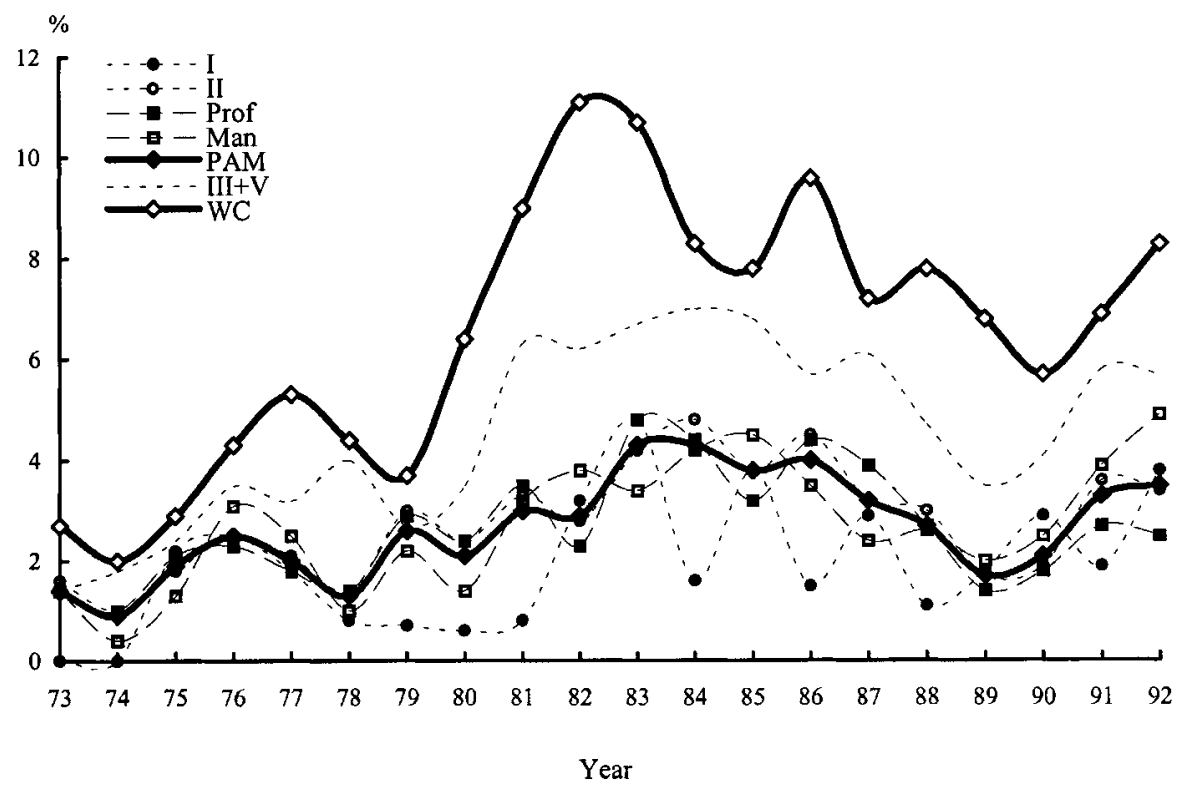

(B) Long-term unemployment lasting over a year

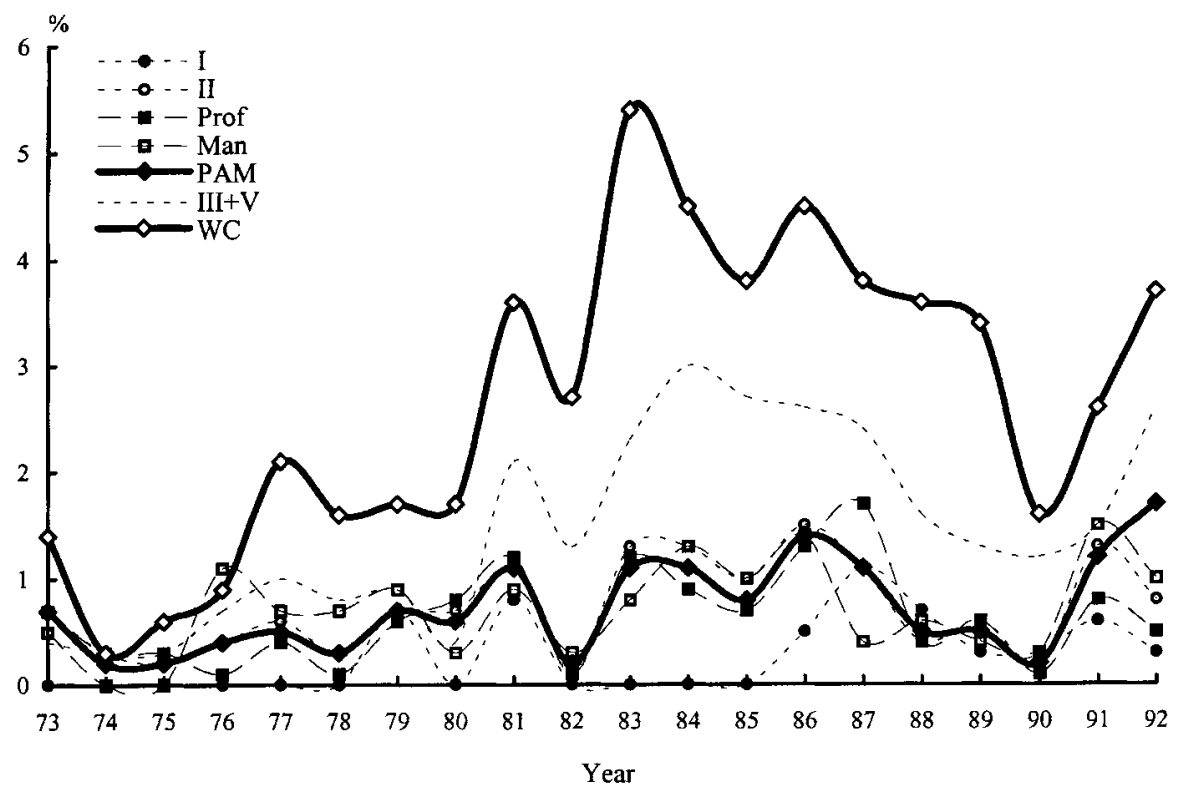

Source: Same as in Figure 5.

Figure 6. Unemployment hazards of women 
career continuity and a low degree of long-range downward mobility; and that, because of the commonality of the employment relationship, professionals and managers will manifest no major divisions. The assets theory holds that the cultural assets of professionals will safeguard their career security and advancement, which will facilitate the formation of a cohesive and stable professional middle class; it also argues that the context-specific and non-transferable organizational assets of managers will result in a highly marginalized and insecure managerial middle class. The evidence suggests much more support for the first than for the second theory. In terms of career trajectory, both entry groups were much more likely to stay in the service class than to move into working-class positions; professionals showed themselves increasingly likely to move into management in their career development; and neither group, which is of considerable importance with regard to the assets theory, undertook self-employment to any noticeable extent. Women managers were more likely to lose career continuity than the other three groups, which is adequately explained by neither theory. With regard to unemployment, managers were as unlikely as professionals, for men and women alike, to suffer unemployment of either kind. The patterns and trends in this regard went much as expected by the employment relationship theory and in direct contrast to the assets theory. While there were somewhat greater situs than echelon differences in career trajectory, differences of an opposite kind were found in unemployment experiences. Differences within the service class, be they situs between professionals and managers, or echelon between the higher and the lower grades, were generally very small. Education played a significant role in career mobility, and the trends of educational association with class integrated rather than divided professionals and managers.

There may be many reasons for the findings and we shall briefly address some. First, the employment relationship theory fully recognizes both the organizational expertise of managers and the specialist knowledge of professionals as very important assets for the smooth and effective running of modern organizations. The emphasis within the assets theory on the contrast between cultural and organizational skills seems to miss the point that modern management is increasingly professionalized, with an increasing number of managers possessing both cultural and organizational assets (Lee and Newby, 1983). Managers are becoming increasingly 'cultured', which erodes the foundation-stone of the theory.

The professionalization of management has been long predicted and confirmed in previous studies. Tawney (1921) envisioned an increasing number of salaried managers performing specialized functions as a welcome sign of professionalism making its way into business. Burnham (1943) saw a well-trained and technically qualified management as a developmental trend. The convergence of the two groups in the pay differentials in the earlier decades was shown by Routh (1980:127) and in the recent past by Elias and McKnight (1997: Table 8.4). The blurring of professional-managerial distinctions was documented in Mills (1995) in terms of 'stocks' and in the present study in terms of 'flows'. The propensity for professionals, especially men, to move into management in the course of career development is viewed by the employment relationship theory as part and parcel of service-class employment, entailing no more than a shift in the technical division of labour. As experienced professionals are increasingly recruited into management to 'manage' both their professional colleagues and others in the production units, it becomes more and more difficult to tell 'true' professionals from 'true' managers. This point is also noted by exponents of the assets theory (Savage et al., 1992: 14-15; 141-3) but apparently not fully appreciated in their pursuit of the 'causal powers' of the 'middle-class' formation.

To end with, there seems good reason to suggest that both organizational and cultural assets are important. The relative weights of the two are hard to measure, but we can be sure that the trend towards the professionalization of management and the resultant professional-managerial convergence are here to stay, as modern management is becoming increasingly complex and requires ever greater cultural components.

\section{Acknowledgements}

I am grateful to John Goldthorpe, Anthony Heath, Angela Dale, Lynn Jamieson, and the anonymous 
referees for helpful comments, to Martin Range and David Firth for technical advice, and to Jane Roberts and Robin Rice for providing the data-sets. I am alone responsible for the errors in the paper.

\section{References}

Bourdieu, P. (1984) Distinction. Routledge \& Kegan Paul, London.

Braverman, H. (1974) Labour and Monopoly Capitalism. Monthly Review Press, New York.

Bruce-Briggs, B. (1979) The New Class? Transaction Books, New Brunswick, NJ.

Burnham, J. (1943) The Managerial Revolution. Putman \& Co., London.

Butler, T. and Savage, M. (1995) (eds) Social Change and the Middle Classes. UCL Press, London.

Dahrendorf, R. (1964) Recent changes in the class structure of European societies. Daedalus, Winter, 225-270.

Elias, P. and McKnight, A. (1997) Earnings, occupations and social classification. In Rose, D. and O'Reilly, K. (eds) Constructing Classes: Towards a New Social Classification for the UK. ESRC/ONS, Swindon, pp. 98-115.

Elliott, J., Dale, A. and Egerton, M. (2001, forthcoming) Returning to work after childbirth: a longitudinal analysis of the role of qualifications in facilitating mother's return to paid employment. In Marshall, V., Heinz W. R., Kreuger, H. and Verma, A. (eds) Restructuring Work and the Life Course. University of Toronto Press, Toronto, p. 505-524.

Erikson, R. and Goldthorpe, J.H. (1992) The Constant Flux: A Study of Class Mobility in Industrial Societies. Clarendon Press, Oxford.

Evans, G. (1992) Testing the validity of the Goldthorpe class schema. European Sociological Review, 8, 211-232.

Goldthorpe, J.H. and Hope, K. (1974) The Social Grading of Occupations: A New Approach and Scale. Clarendon Press, Oxford.

Goldthorpe, J.H. (1982) On the service class, its formation and future. In Giddens, A. and Mackenzie, G. (eds) Social Class and the Division of Labour: Essays in Honour of Ilya Neustadt. Cambridge University Press, Cambridge, pp. 162-185.

Goldthorpe, J.H. (1984) Women and class analysis: a reply to replies. Sociology, 18, 491-499.

Goldthorpe, J.H. (1995) The service class revisited. In Butler, T. and Savage, M. (eds) Social Change and the Middle Classes. UCL Press, London, pp. 313-329.
Goldthorpe, J.H. (with Llewellyn, C. and Payne, C.) (1987) Social Mobility and Class Structure in Modern Britain. Clarendon Press, Oxford.

Gouldner, A.W. (1979) The Future of the Intellectuals and the Rise of the New Class. Macmillan, London.

Lee, D. and Newby, H. (1983) The Problem of Sociology. Hutchinson, London.

Li, Y. (1997) The Service Class: Theoretical Debate and Empirical Evidence. D.Phil thesis (Oxford).

Marshall, G., Newby, H., Rose, D. and Vogler, C. (1988) Social Class in Modern Britain. Hutchinson, London.

Martin, J. (1997) Social class, SEG and Goldthorpe classes: how do they classify individual occupations? In Rose, D. and O'Reilly, K. (eds) Constructing Classes: Towards a New Social Classification for the UK. ESRC/ONS, Swindon, pp. 49-61.

Mills, C. (1995) Managerial and professional work histories. In Butler, T. and Savage, M. (eds) Social Change and the Middle Classes. UCL Press, London.

Morris, R. and Murphy, R. (1959) The situs dimension in occupational structure. American Sociological Review, 24, 231-239.

Renner, K. (1953) The service class. In Bottomore, T. and Goode, G. (1978) Austro-Marxism. Clarendon Press, Oxford, pp. 249-252.

Rose, D. and O'Reilly, K. (1997) (eds) Constructing Classes: Towards a New Social Classification for the UK. ESRC/ ONS, Swindon.

Routh, G. (1980) Occupation and Pay in Great Britain 1906 79. Macmillan, London.

Savage, M., Barlow, J., Dickens, P. and Fielding, T. (1992) Property, BureaucracyandCulture: Middle-class Formation in Contemporary Britain. Routledge, London.

Tawney, R.H. (1921) The Acquisitive Society. Bell, London. Wajcman, J. (1996) Desperately seeking differences: is management style gendered? British Journal of Industrial Relations, 34, 333-349.

Wright, E.O. (1985) Classes. Verso, London.

\section{Author's Address}

Centre for Census and Survey Research, Dover Street, Manchester University, M13 9PL, UK. Tel.: 00-44161-275-4836; fax: 00-44-161-275-4722; email: yaojun (a) man.ac.uk.

Manuscript received: May 2000. 